\title{
Materials Research in France: A Short-lived National Initiative (1982-1994).
}

Emanuel Bertrand, Physico-chimie des Electrolytes, Colloïdes, et Sciences Analytiques (PECSA), UMR 7195 - UPMC - CNRS - ESPCI ParisTech, Universite Paris 6 Pierre et Marie Curie, case courrier 51, 4 place Jussieu, 75252 Paris cedex 05, France.

Bernadette Bensaude-Vincent, Université Paris 1 Panthéon-Sorbonne/IUF, Centre d'Etudes des Techniques, des Connaissances et des Pratiques (CETCOPRA), 17 rue de la Sorbonne, 75231 Paris cedex 05, France.

\begin{abstract}
This paper describes the French initiative in materials research against both a national and an international background, in an attempt to disentangle the local circumstances, which prompted this governmental initiative, and to characterize the specific profile of materials research in France. In presenting a biography of the interdisciplinary program in materials research (PIRMAT), we argue that: i) the PIRMAT denotes a failure of the French science policy in materials research; ii) the leadership of the CNRS led to a specific style of research, quite different from the engineering approach of Materials Science and Engineering, and characteristic of a French style in materials research.
\end{abstract}

\section{Keywords Materials science - Engineering - Science policy - National style - Interdisciplinarity}

Materials Science emerged as a new entity embracing all kinds of materials - from wood, to metals, ceramics, semi-conductors and composites - in many industrialised countries over the second half of the twentieth century. Such a field of research required interdisciplinary structures, which were implemented through national science policies. In France, an interdisciplinary program, the PIRMAT (interdisciplinary program in materials research) was launched in 1982. Like the US program of interdisciplinary laboratories initiated in the early 1960s, the PIRMAT resulted both from a combination of the inner dynamics of a number of scientific communities, and from a political decision. In the French case, an impulse was given, in 1982, by the newly formed socialist government. However, unlike the US program which created Materials Science and Engineering (MSE), the French initiative was rather short-lived, and did not result in the creation of materials science centres in universities.

Based on institutional archives crossed with oral testimonies, this paper tells the biography of the short-lived PIRMAT. It describes the French initiative in materials research against both a national and an international background, in an attempt to disentangle the local circumstances, which prompted a governmental initiative in the field, and to characterize the specific profile of materials research in France.

This case study raises a broader historiographical issue: How are we to evaluate the success or failure of the French program? It is tempting to use its American counterpart as the standard for success, since Materials science emerged while the USA were supporting the reconstruction of European research following World War 2, and played a key role in shaping national science policies (Krige 2006). NATO meetings were organized to spread the US model in Europe (NATO 1963). Unsurprisingly, issues of national differences came up again and again over the course of our interviews with materials scientists. From our perspective, national differences should be accounted for in terms of national styles rather than in terms of 
time lag. ${ }^{1}$ Thus the French program is evaluated against its own objectives and ambitions, and we consider international comparisons an integral part of the story.

We stumbled upon the issue of national comparisons from the outset, since different countries used different names for the topic of our historical inquiry. The very name Materials Science and Engineering (MSE) was coined in the USA and does not necessarily reflect the situation in other countries, where materials research did not become institutionalized as a new hybrid science. As soon as we tried to apply the phrase "materials science and engineering" to describe the French case, we identified all the obstacles, impediments, prejudices, conservatisms, which would become the ingredients of a non-success story.

The ambition of this paper is to characterize a French style in materials research. To this end, we will discuss the following issues: To what extent did the Centre national de la recherche scientifique (CNRS) create a specific and favourable context for the emergence of materials science in France? What was the impact of the government, and the input from the industry? And, finally, is it possible, and is it worth assessing national programs without resorting to international ranking?

\section{The Context}

\subsection{The Hegemony of the CNRS}

The French research agency named CNRS ${ }^{2}$ was officially created in 1939 to provide regular incomes for full-time researchers, in all research areas, and to coordinate scientific research at a national level. It enjoyed such a high-level of autonomy that it was described by a historian as a "republic of scientists" (Picard 1990). Since 1945, the National committee, in charge of the CNRS researchers' recruitment and evaluation, has been structured into disciplinary sections.

In compliance with the US support to European research in the 1950s and 1960s, the CNRS policy was mainly oriented toward fundamental research. The US program of support to European scientific programs was based on a clear-cut distinction between basic research that was financially supported - and applied research, which was not encouraged, and even forbidden for all military applications (Krige 2006). However, no strict control was needed, since there was a consensus around the linear model, i.e. the view that fundamental research is a precondition for technological advances (Godin 2006). Thanks to generous funding from the Rockefeller foundation, and to a significant increase in the French research budget in the 1960s, a number of centres sporting cutting-edge instrumentation quickly acquired international recognition. In the 1970s, the CNRS encouraged collaborations with industrial research, and CNRS/industry joint laboratories (laboratoires mixtes) were created. In 1975, a new department of engineering sciences (SPI for Sciences physiques pour l'ingénieur) was created, and interdisciplinary research programs (PIR for Programme interdisciplinaire de recherche) were launched. The first PIR was devoted to solar energy (PIRDES). In addition, new sources of funding became based on themed invitations to tender such as the

\footnotetext{
${ }^{1}$ See, for instance, Cottrel (2000). For a British view, see Cahn (2001). For a critical perspective on the centreperiphery perspective on materials research, see Bensaude-Vincent and Hessenbruch (2004).

${ }^{2}$ More information about the history of the CNRS in Picard (1990), Guthleben (2009), and in La Revue pour l'Histoire du CNRS, esp. N¹ (1999): "Le CNRS au temps de Charles de Gaulle: 1958-1969", N² (2000): "Les premiers laboratoires du CNRS", $N^{\circ} 11$ (2004): "Le CNRS au sein du dispositif de recherche français: ses relations avec d'autres organismes". For a broader view of the organization of the French research system, see Shinn $(1980,1994)$.
} 
programmed thematic actions (ATP for Actions thématiques programmées) and research networks (GRECO for Groupements de recherches coordonnées).

In brief, the French national policy followed the general model imposed by the "American hegemony" on European research in the aftermath of WW2. However, unlike the USA and the UK, France rebuilt its research potential under the leadership of the CNRS, and independently of universities. The creation of novel research agencies dedicated to applied research such as the Atomic Energy Commission (CEA) in 1945, the National Institute for Agricultural Research (INRA) in 1946, the National Institute for Medical Research (INSERM) in 1964, only served to reinforce the CNRS' dedication to fundamental research in all areas. Indeed, while universities were also part of the research landscape, they declined because they were never able to benefit from the high levels of autonomy and funding CNRS laboratories had (Bourdieu 1984, p. 270). In addition, few engineering schools were able to conduct cutting-edge research. Thus the CNRS gained a virtual monopoly on French fundamental research, and an international reputation, as exemplified by a number of Nobel laureates. Retrospectively, the 1950s and the 1960s are often described as the golden age of fundamental research in France.

\subsection{Strong Academic Communities}

In order to fulfil its multidisciplinary ambition, the CNRS was structured along disciplinary lines, including a few large departments employing increasing numbers of fulltime researchers. ${ }^{3}$ This disciplinary structure allowed the emergence of many sub-disciplines within each department. In particular, solid-state physics quickly became established within the mathematics and physics departments, and solid-state chemistry within the chemistry department. Interdisciplinary networks also developed in the 1960s and 1970s, thanks to the institution of summer schools, which, according to its actors, played a key role in the emergence of a "materials way of thinking".

In particular, a strong community of solid-state physics developed in two major centres: Paris and Grenoble. In Grenoble, a centre dedicated to magnetism nucleated around Louis Néel: The Centre Laue-Langevin, created in 1967 with rich equipment, became a prestigious research centre for electronics and microelectronics. Néel developed a research school around semi-conductors, characterized by a close alliance between theoretical and experimental physics (Pestre 1990).

In Paris, solid-state physics was more a continuation of metallurgy. Between 1959 and 1989, a doctoral program in solid-state physics chaired by Jacques Friedel at Orsay University, in the South of Paris, provided solid theoretical and experimental training for an entire generation. Friedel, the heir of a brilliant scientific dynasty, did his PhD with Nevill Mott in Bristol. Over thirty years, he managed a research school focused on dislocations and the electronics of solids, which developed sophisticated techniques (ultra-vacuum, in situ characterization, etc) to investigate bulk materials and surfaces. When Pierre-Gilles de Gennes joined the group in the 1960s, the research area gradually extended to include the investigation of liquid crystals and polymers. In the $1970 \mathrm{~s}$, the solid-state physics community turned to less-conventional materials, such as the amorphous disordered states of matter. The phrase "dirty physics" was often used to refer to this kind of research.

This community was cemented by a series of summer schools in Les Houches, a ski resort in the French Alps, which proved vital for the reconstruction of research. In the 1960s, the summer schools brought together metallurgists and physicists, and were also opened to

\footnotetext{
${ }^{3}$ From about 350 researchers in 1945 to about 1000 in the 1960 s and 10000 in the 1980 s (Guthleben 2009, p. 371).
} 
industrial researchers and foreign scientists. Over the years, they focused on specific topics such as "physics of ill-condensed matter" in 1978 and defects in 1980.

Given that most of the topics covered by the solid-state physics communities belong to materials science, should we describe it as the first step in the emergence of this discipline in France? The Orsay group certainly did foster continued interactions between physicists and chemists, and included contacts in industrial companies manufacturing glass, aluminium and electric cables. Interestingly, most of the actors we interviewed did not feel they had been working on materials science. They stressed the distance between their academic perspective and the engineering perspective that prevailed in MSE. For instance, Friedel argued that in France, materials science did not emerge until a governmental initiative was launched by the Direction générale de la recherche scientifique et technologique (DGRST) in 1970-71, out of a "concerted action" between metallurgists and physico-chemists, with a strong slant towards using an engineering perspective. In other words, the emergence of materials science is presented as a top-down political decision, rather than a bottom-up process resulting from the inner dynamics of academic research. This French insiders' view differs from the selfrepresentation developed by some of the major actors in the USA - Bernhardt Wuensch and Mildred Dresselhauss for instance ${ }^{4}$ - and from the standard narrative published by Robert Cahn in the UK (Cahn 2001). This contrast may be due to the exclusive focus of French solidstate physicists on structure-properties relationships, with no attention to performances and processes.

In parallel to the solid-state physics community, a community of solid-state chemists emerged. And this seems to be a French peculiarity. While, in the USA, a niche was provided by MSE for solid-state chemists (DiSalvo 1990), in France, they created a new branch of chemistry, named "chimie du solide" (Teissier 2007). The community attracted so many young researchers that it increased from about 100 people in the late forties to over 500 , and 40 laboratories, in the mid-1960s. Three different topics prevailed in the 1950s and 1960s: Solid-state reactions in non-stoichiometric oxides, high temperature chemistry of refractory materials, and metal oxides. French chemists thus provided refractory ceramics to the nuclear and space industries, and magnetic oxides as recording materials. In the 1960s, they became experts in crystal-genesis (required for semi-conductors); they also designed optical rare earth compounds for TV screen pigments. Later in the 1970s, they focused on ionic superconductors for the energy and automotive industries. Unlike solid-state physicists, they went beyond structure-properties relationships, and developed an interest in "propertyperformance relationships", which provided the funding they depended on.

The solid-state chemistry community was a fragmented world, dominated by charismatic leaders - Robert Collongues in Paris, Paul Hagenmuller in Bordeaux -, with a kind of tacit agreement between research groups which roughly divided labour based on a split of the periodic system, thus giving each group their own turf. In addition, the community, which developed around the topic of mineral chemistry, had virtually no contact with the physico-chemists who developed surface science or catalysis (Voillequin 2008).

In summary, even before the national initiative on materials was created, a variety of materials - solids, liquid crystals, semi-conductors, ionic conductors, catalysts and more exotic powders - had been the subjects of intense research efforts in France. Such research had developed within distinct disciplinary contexts under the aegis of the CNRS. It was a state-dependent research mainly pursued by academic scientists. They occasionally collaborated with industrial research laboratories, but their careers and research pathways did not depend on industrial funds.

\footnotetext{
${ }^{4}$ Interviews of B. Wuensch, Jan. 9, 2001, of M. Dresselhauss, Oct. 25, 2001, and of R. Cahn, Dec. 6, 2000 , by B. Bensaude-Vincent and A. Hessenbruch. See all these interviews on the website http://www.sho.espci.fr/ (under construction). See also DiSalvo (1990).
} 


\subsection{Materials Science as an Objective (1977-81)}

In the late 1970s, materials research became a political concern. In 1979-1980, the DGRST asked Friedel to survey the state of the art in materials science, with a view to defining the French research strategy for the next ten years. Friedel's report highlighted a number of strong points (physico-chemistry of materials and surface science) as well as weaknesses such as the virtual absence of interaction between the investigation of mechanical properties of materials and their chemical structures. This report focused on academic research, although Friedel was a member of the scientific board of the industrial group SaintGobain.

The first impulse toward an interdisciplinary program on materials came from within the disciplinary structure of the CNRS itself. The "mathematics and physics department" of the CNRS launched the first call for tenders on materials science in August 1977. The "materials thematic programmed actions" ("actions thématiques programmées matériaux") targeted three classes of materials: Amorphous materials and liquids; interstitial compounds with great ionic mobility; selective absorption compounds for photo-thermal conversion of solar energy. Only nine proposals were selected and funded for 18 to 24 months. The total budget for all three actions came from the CNRS, and was about one million French Francs (FF), which is approximately equivalent to 500000 EUR today. Although these calls for tenders were renewed every year for four years, in 1978 and 1979, the term "materials" disappeared from the title of the call, which became "physics and chemistry of condensed matter" in 1978 and "physico-chemistry of condensed systems" in 1979, both with a budget of FF 2.5 million.

Materials science only appeared as an explicit objective in 1980, when three CNRS departments jointly launched a call for tenders: "mathematics and physics", "chemistry" and "engineering sciences". This call targeted four different research areas: i) "Materials with peculiar physical and chemical properties" (organic solids, composites and amorphous materials, thin films...); ii) "Plasticity of solid materials" (deformations, defects, cracks, failures...); iii) "Sintering of metallic powders and ceramics"; iv) "Physico-chemistry of surfaces and interfaces". The funding of FF 6.6 million (about 2.5 million EUR) came both from the CNRS (FF 3.1 million) and the DGRST (FF 3.5 million). ${ }^{5}$ This suggests a real convergence of efforts to promote materials science, at least on the academic stage. Looking at the location of the laboratories funded by this call in 1980, one can make out a kind of map of materials research in France in 1980, which reveals a homogeneous distribution all over the French territory. ${ }^{6}$ But the call fell short on its objective to promote interdisciplinarity, since only 3 of the 33 funded projects involved both a physics and a chemistry laboratory. In addition, it is important to note that the French research effort on materials did not solely come from this ATP scheme. Chemistry remained a disciplinary niche for initiatives on "fine chemistry" with a total budget of FF 4.5 million, which included a theme centred around the "synthesis of original materials" for FF 1.5 million.

\subsection{A French Exception?}

\footnotetext{
${ }^{5}$ The 1981 "materials science" call for tenders, financed with FF 4.3 million from the CNRS and FF 3 million from the DGRST, was also focused on "random macroscopic media" (or "MIAM" for Milieux aléatoires macroscopiques).

${ }^{6} 22$ laboratories from the Paris area, 3 from Lyon, Marseille, Strasbourg, Poitiers, Caen and Montpellier, and 2 from Lille, Grenoble, Nancy, Bordeaux and Toulouse.
} 
Thus, the earliest French initiative dedicated to materials research was born almost twenty years after the American initiative launched by the Advanced research projects agency (ARPA). Does it mean that France was lagging behind the USA?

In the USA, the academic interdisciplinary entity referred to as Materials Science and Engineering (MSE) was first inspired by the national space and military programs, and later stimulated by commercial competition (Bensaude-Vincent 2001). In the early 1960s, the federal government created MSE departments in a number of universities, based around laboratories equipped with some state-of-the-art instrumentation meant to encourage collaborations between researchers from physics, chemistry and engineering departments. This instrument-driven "interdisciplinary discipline" was fully described in a 1975 report by the National Academy of Sciences. ${ }^{7}$ MSE was characterized by three associations: i) It coupled scientific research with engineering application of the end-product; ii) It drew together different fields of science and engineering: Metals, ceramics, electrical engineering, chemical engineering, physics, inorganic chemistry, organic chemistry, crystallography, etc; iii) It required collaboration between different kinds of agents: industrial corporations, governmental agencies, and universities.

In the early 1980s, as France was about to launch its own national initiative, MSE underwent two major changes in the USA. First, the Bayh-Dole Act, passed by the US Congress in 1980, allowed any result arising out of federally funded research to be patented. The Act successfully redirected academic work toward the generation of intellectual property, and $R \& D$ for consumer markets. At the same time, processing rose to greater prominence within MSE, thus reinforcing the alliance between science and engineering.

In France, by contrast, materials mainly remained within physics and chemistry, and prompted interactions between these two communities only. Materials research was not promoted as a new discipline bringing together science and engineering. Rather, it was an academic initiative based on existing scientific communities, and under the guidance of the CNRS, with occasional connections with industrial corporations, and no real concern for commercial applications. To what extent would the governmental initiative launched in 1982 change the situation?

\section{The National Initiative (1982)}

\subsection{The Political Turn}

In 1981, the presidential elections brought about a socialist leader, François Mitterrand. His new minister for research and technology, Jean-Pierre Chevènement, organized a national consultation ("Assises régionales de la recherche"), before reforming the French system of research in the midst of great hopes and enthusiasm. This process resulted in an Act of Parliament ("Loi d'orientation et de programmation", July 15, 1982) programming research and development, which had been declared a "national priority". The new government's policy was clearly set out in the Act: One of its major objectives was to strengthen the links between academia and industrial firms. In parallel, a large part of the research budget was devoted to the nation's industrial development, and to its economic competitiveness. Remarkably, these orientations also translated into a name change, for Jean-Pierre Chevènement's ministry became "ministry of research and industry" on June 29, 1982.

\footnotetext{
${ }^{7}$ National Academy of Sciences (1975), Vol. I, Chap. 1. The same report defined MSE: "Materials science and engineering is concerned with the generation and application of knowledge relating to composition, structure, and processing of materials to their properties and uses" (Vol. I, Chap. 2, p. 2).
} 
The links between public research and industry were immediately facilitated by another law of February 1982, which nationalized large industrial corporations. Most of them were linked to materials: Thomson-CSF to materials for electronics; Saint-Gobain to glass and innovative materials (ceramics, crystals, plastics); Rhône-Poulenc to polymers; Pechiney to aluminium; CGE (renamed Alcatel-Alsthom in 1991) to telecommunication and railroad materials; Usinor and Sacilor (which merged in 1986) to iron, cast iron and steel.

At the same time, the proportion of R\&D in the NGP raised above 2\%. As Pierre Papon was appointed director of the CNRS in September 1982, the budget of the CNRS increased by $25 \%$. Although the majority of the CNRS' budget was devoted to paying the wages of researchers (who became permanent civil servants), the budget devoted to interdisciplinary programs was maintained.

\subsection{A Pragmatic View}

In 1982, Chevènement commissioned a report on materials research in France from Jean-Pierre Causse. A physicist, trained at the École normale supérieure, Causse had worked for Schlumberger in the USA from 1954 to 1962. In 1981, he was at the head of Saint-Gobain research. Causse thus embodied the alliance between the socialist government and industrial milieus, which was meant to bring about a radical change to materials research.

The panel in charge of the report included few members, none from universities, and most from large state agencies dedicated to applied research. ${ }^{8}$ The panel completed its report in three months. There was no time, or no inclination to travel abroad, for example to see how MSE was implemented in other industrial countries. The report subsequently never mentioned the US as a model.

The report pinpointed two strong points: glass and aluminium, and deplored the lack of interdisciplinarity, of young researchers and of connections between academic research and industry. This latter weakness is illustrated by the case of liquid crystals, a domain in which France failed to develop an industry, even though it was at the forefront of academic research. ${ }^{9}$

The concept of materials promoted by Causse's mission deeply differed from the notion that prevailed in academic research. Whereas before, the focus had been on structureproperties relations, in Causse's report, the users' perspective prevailed. ${ }^{10}$ Materials were approached according to their domains of application, and, from the outset, the ambition of covering all domains was abandoned. A few sectors were selected as priorities: materials for electronics, for construction, and for mechanical structures.

The report clearly aimed to bring together science and engineering: The study of structure/properties was to be complemented by research on design and fabrication processes, as well as on materials resistance and ageing. Process had to become an integral part of materials research, thus requiring a dialogue between industry and academics. Even though Causse's report was not inspired by the American model, it encouraged a similar "materials

\footnotetext{
${ }^{8}$ Jacques Balazard was the technical director of the Aérospatiale, Jérôme Bédier was in charge of the rubber and plastic division at the Ministry of industry, Guy Bessonnat belonged to a research agency of the army (DRET), Jacques Boileau to the national explosives manufacture (SNPE), Jean Hanus came from the CNRS, Jean Jerphagnon from the CNET (national center for research on telecommunications), Gilles Pomey from the materials department of the École des mines de Paris, and Pierre-François Gobin, rapporteur of the commission, from the materials department of the Ministry of research and technology.

${ }^{9}$ J.P. Causse, interview with B. Bensaude-Vincent, Mar. 31, 2009. All quotations of French speakers are our translations.

10 "Les Matériaux. Synthèse des propositions du rapport remis à M. Jean-Pierre Chevènement, ministre de la recherche et de l'industrie”, Sep. 1982, CNRS archives 010035-15. This synthesis adopted a conventional definition of materials as "a set of solids (or fluids) for the design of objects used by man" (p. 1).
} 
way of thinking" from structure to properties to process and performance, in complete contrast to the previously prevailing linear model. ${ }^{11}$

The report balanced the interests of academic and industrial actors with strong statements such as: "[Materials research] should anticipate industrial needs, but be disconnected enough to ensure continuous and rather independent advances based on its own dynamics". ${ }^{12}$ However, the four major objectives assigned to materials research clearly show the prevalence of industrial and social concerns: i) To decrease the vulnerability of France with respect to energy and raw materials supply; ii) to keep a commercial balance between imports and exports; iii) to create permanent jobs; iv) to secure the success of future technological programs.

The report recommended promoting high-level materials science research, and selecting a few priorities for specific R\&D efforts. Two major concerns guided these recommendations. Firstly, to avoid subverting existing scientific and industrial networks, the programme deliberately adopted a pragmatic approach devoid of revolutionary claims. Secondly, it tried to avoid dispersing funds between too many topics, and concentrated the research effort on a few national priorities, which could place France in a leading position on the international market.

The report accordingly recommended a state budget of one billion FF over three years (1983-85), including 700 millions to be allocated to research priorities, while the remaining 300 million served to maintain research on pre-existing topics. The resulting selection of priorities suggests a tentative compromise between an industrial logic (leading to a sectoral approach to materials) and a scientific approach, more concerned with general laws applicable to all species of materials.

Such type of compromise is not a specific feature of the French strategy. A quick glance at the annual meetings organized by the American Materials Research Society (MRS), founded in 1973, reveals similar negotiations between conflicting logics. Despite choosing generic themes aimed to develop trans-material concepts and foster the unity of MSE, thematic meetings were gradually replaced by simultaneous sectoral symposia which increased the number of participants and contributed to the success of the annual meetings (Roy 1993). Thus, the compromise between specific and generic perspectives on materials is by no means typically French. Instead, it seems to be a major feature of the entire field of materials research.

\section{The PIRMAT (1982-1994)}

\subsection{Institutional Implementation}

How did the recommendations from Causse's report actually translate into practice? Firstly, because the report recommended taking into account existing research groups, the creation of a big "materials centre" was discarded in favour of an incentive programme "fostering, coordinating and promoting fundamental research which could contribute to solving materials problems within the CNRS and associate laboratories." $" 13$

Who would manage the programme named PIRMAT? Since Causse's panel had no executive power, this crucial decision laid in the hands of the CNRS. Robert Chabbal, a

\footnotetext{
${ }^{11}$ In the 1980s, US MSE courses and textbooks recommended a specific method for designing materials, based on four parameters: structure, properties, performances and processes. Changes made in any of the four parameters could impact on the balance of the whole system and require a re-thinking of the whole device. 12 "Les Matériaux. Synthèse..." op. cit., p. 3.

13 “CNRS - Schéma directeur du PIRMAT 1982”, CNRS archives 000029-31, p. 2.
} 
physicist, and former general director of the CNRS (1976-1979), was designated to implement the panel's recommendations.

PIRMAT was a joint production of three CNRS departments: Mathematics and basic physics, chemistry, and engineering sciences. The scientific board of PIRMAT included four members from each CNRS department, plus one member from the National institute for nuclear and particle physics (IN2P3), twelve representatives from the industry, one representative from the ministry of research and technology, and one from the ministry of education. The implementation process thus transferred most of the responsibility to the CNRS, and consequently put much emphasis on fundamental research.

A physicist, Jean Hanus, was chosen to manage PIRMAT. Hanus did a PhD at MIT at the time when the US interdisciplinary labs were created, between 1959 and 1962, and this experience may have led him to favour a US model-based policy. He later spent three years at the Lincoln Laboratory, a military laboratory at the forefront of materials research, between 1966 and 1969. However, when he became an associate member of the CNRS, he quickly realized that creating a permanent interdisciplinary structure within the disciplinary compartments of the CNRS would be impossible. Hanus thus summarized the situation: "Pierre Papon suggested [the creation of a materials department] but he confronted the opposition of the community. Physicists despised chemists, mechanics were a world apart. To study materials, mechanics, physicists and chemists were all like exclusive parents. [...] I knew it was a desperate battle". ${ }^{14}$

In a special issue of Le Courrier $d u$ CNRS (Sep-Nov 1983), Hanus clearly stated that PIRMAT's mission was to act as a bridge between the demands of the industry and the "spontaneous dynamics of the scientific domain". To that end, he announced a special effort on equipment, for the design and characterization of materials, and the creation of interdisciplinary networks among the 750 researchers working in the field. The PIRMAT agenda officially included five tasks ${ }^{15}$ : i) To conduct prospective on materials fundamental research; ii) to launch and support annual incentive actions; iii) to fund "semi-heavy instrumentation" through partnerships between the CNRS, the ministry of research and technology, the ministry of education and other state research agencies; iv) to integrate research on materials design processes; v) to coordinate collaborations at national level between various partners, including administrations, state research agencies and industry.

In reality, the French materials initiative did not result in an ambitious program. Instead, PIRMAT became one of the French science establishment's modest efforts to encourage interdisciplinary work. Despite its emphasis on the strategic place of materials in increasing national wealth, and recommendation that big investments should be made, Causse's report did not prompt any radical measures. And PIRMAT became a way of re-directing existing research pathways rather than creating new avenues.

\subsection{Epistemic Choices}

What definition of materials did the French promoters of materials research have in mind when they shaped PIRMAT?

A first striking feature is the lack of any homogeneous view or definition of what materials may be. For Causse, "a material is, above all, the stuff things are made of. Materials are man-made". ${ }^{16}$ This general and abstract definition clearly links materials to human technology rather than to physical sciences. It reflects the view that the age of "materials by design" had arrived. In this vision, materials could be shaped according to required specific

\footnotetext{
${ }^{14}$ J. Hanus, interview with B. Bensaude-Vincent, May 16, 2007.

15 "Décision de création du PIRMAT", Mar. 8, 1982, CNRS archives 850180-2.

${ }^{16}$ Le Courrier du CNRS, ${ }^{\circ}$ 52-53, Sep-Nov 1983, p. 7.
} 
performances, thus matter should no longer be a limiting factor for technological projects. By contrast, Jean-Pierre Philibert, a physicist, adopted the standard definition of materials, based on the relationship between structure and properties, used in physical sciences. ${ }^{17}$ In this case, the emphasis was on the multi-scale approach, whereas Jean Rouxel, a chemist and founder of the Materials centre in Nantes, exclusively focused on the molecular level when reporting his research on intercalation materials. ${ }^{18}$

A second striking feature of the French program designed in 1982 is that it presents a collection of approaches to studying materials, but does not attempt to classify materials themselves. Rather, it offers an impressionist view of current trends through samples of the different approaches to materials science. The people in charge of this project were so convinced of its legitimacy, that they did not feel the need to provide a sound conceptual basis for a materials program.

The basic assumption underlying PIRMAT was that materials already existed as a generic entity. The first PIRMAT brochure insisted on "the great unity of the domain when considering fundamental research, design and control processes. It is this unity of Materials science and engineering, which makes it possible to coordinate an action at a national scale, through the implementation of an incentive program and the creation of PIRMAT within the CNRS". ${ }^{19}$ This assumption is also conveyed by the phrase: "le fait materiaux", which was coined in describing PIRMAT. It conveys the view that the generic concept encompassing all materials - from semiconductors and high-tech materials to wood and paper - was a matter of fact. Given that the unity of materials science was taken for granted, the people in charge of PIRMAT were not overly concerned by the construction of a generic knowledge, which could be achieved through using concepts applicable to all types of materials, common methods and standardised instruments to characterize or measure performances.

Another assumption was that instruments such as electron microscopes, flux neutron reactors, synchrotrons, and so on, helped make materials science predictive, but that materials science still lacked theoretical foundations. Such admission could have prompted efforts to overcome this lacuna. Yet there was no general agreement on the importance of theory. It was not a priority for Causse, who claimed that: "The role of theory should not be overestimated in materials science: Theory is established in the relations between the structures and properties of the products under scrutiny". ${ }^{20}$

The brochure "PIRMAT directive scheme 1982" included a visual representation of its underlying notion of materials, which maintained a clear distinction between science and engineering, between ideal and real. ${ }^{21}$ Despite double arrows suggesting interactions, this chart presents a revised version of the linear model rather than a systems approach:

\footnotetext{
${ }^{17}$ Ibid. p. 12: "We shall call 'materials' solid bodies (exceptionally, condensed fluids), crystallized or not, homogeneous or made of more or less complex aggregates. Basic properties of materials deal with 'structure', a term that covers many scales: electronic, atomic, or polyatomic (crystalline aggregates, phases)".

${ }^{18}$ Ibid. p. 18-20.

19 “CNRS - Schéma directeur du PIRMAT 1982”, CNRS archives 000029-31, p. 1.

${ }^{20}$ Le Courrier du CNRS, n ${ }^{\circ}$ 52-53, Sep-Nov 1983, p. 11.

21 “CNRS - Schéma directeur du PIRMAT 1982”, op. cit., p. 3.
} 
Models, Ideal Materials
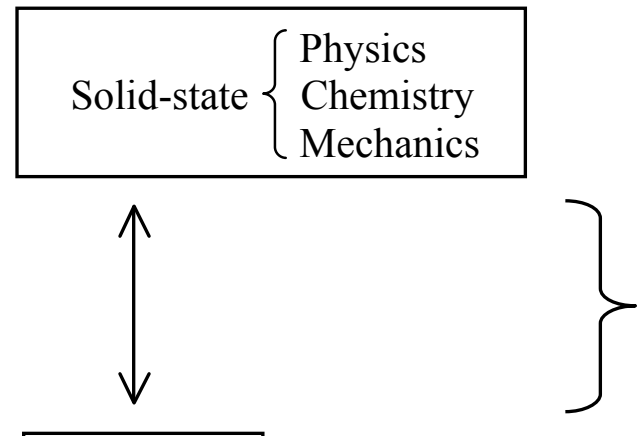

Materials Science

Structure/Properties

Real Materials

Materials

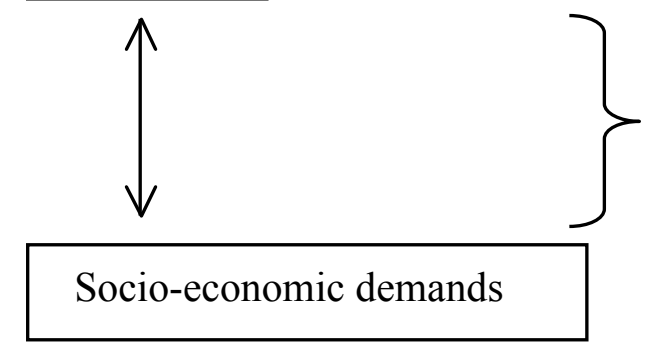

Materials Engineering

Design

Performances

Cost

\subsection{The Two Lives of PIRMAT}

Two periods may easily be distinguished when considering PIRMAT's brief lifespan: a period of establishment, in the hands of Hanus, and a period of decline, in the hands of his successor.

Once appointed director of PIRMAT, Hanus had to organize a steering committee. Since he belonged to "mathematics and basic physics" department, he statutorily chose two co-directors from the two other CNRS departments involved in PIRMAT. He appointed Annick Percheron-Guégan, a solid-state chemist from the chemistry department, and Joseph Baixeras, an electronics engineer from the engineering sciences department. Jean-Pierre Vairon, a polymer chemist, André Zaoui, a mechanical engineer, and Claire Dupas, a physicist specialized in magnetism, were chosen as the three additional members of the committee.

The first PIRMAT call for tenders, launched in September 1982, suggests the prevalence of research on specific types of materials ( 8 actions), over transversal research topics (3 actions). The projects selected already departed from the line of Causse's report: Nothing on energy and matter saving processes, or materials for housing, materials for electronics, or wood, which had all been identified as research priorities in the report. ${ }^{22}$

In 1983, Pierre Papon secured a budget line for PIRMAT, which was independent from the disciplinary departments, and which increased from one million in 1983 to FF 9 million, its highest value, in 1986.

In May 1984, a great national conference on materials was jointly organized by the CNRS and the ministry of research and industry to reinforce the relationship between academic and industrial researchers. It was considered a success, with one third of the speakers and over half of the 450 participants coming from industry. ${ }^{23}$ In April 1985,

\footnotetext{
${ }^{22}$ The PIRMAT selection of transversal topics included: plasticity of materials, surfaces and interfaces, and influence of gravity on the transport properties of fluids in contact with materials.

${ }^{23}$ List of participants to the Colloque national matériaux, 1984, CNRS archives 900021-17.
} 
materials science was officially cited as one of the twenty strategic themes for the CNRS ${ }^{24} \mathrm{~A}$ second national conference on materials, held in Paris in January 1986, gathered approximately 600 participants, with a good balance of academia and industry.

However, as an indirect consequence of right-wing parties' victory in the French legislative elections, PIRMAT's flourishing existence suddenly came to halt in March 1986. In June 1986, Papon was replaced by Serge Feneuille, who was clearly hostile to interdisciplinary programs, at the head of the CNRS. ${ }^{25}$ Feneuille decided to integrate PIRMAT within the disciplinary departments. Thus, PIRMAT became attached to the department of chemistry. Hanus protested in vain in a letter to Feneuille, on September 10: "Once attached to the chemistry department, will PIRMAT still speak in the name of the CNRS, or in the name of the chemistry department? Or, rather, will the chemistry department speak in the name of the CNRS when materials are concerned? This point is not innocent". ${ }^{26}$ The budget of PIRMAT was significantly reduced, due to both a global budget cut at the CNRS, and the end of the ministry of research's contribution. In the period 1987-1989, PIRMAT ceased to have the freedom to select its own incentive actions.

With the comeback of the left in Parliament in 1988, Feneuille was replaced by François Kourilsky as the head of the CNRS, where he remained until 1994. Kourilsky, a MD and a biologist, increased the number of interdisciplinary programs and their visibility. However, PIRMAT never recovered its status. All of its directors resigned: Baixeras in 1988, Percheron-Guégan in 1989, and Hanus on December 1, 1989. In his resignation letter addressed to Kourilsky, Hanus wrote: "In the CNRS and in PIRMAT, I have had great joys and several satisfactions. During the last period, it has been more difficult... Today, it doesn't really seem like I am leaving the CNRS, but rather that the CNRS has already left me..."27

This crisis prompted an audit of PIRMAT. Its conclusions were that: i) PIRMAT should be renewed; ii) It should be placed under the direct management of the CNRS' director (the integration of the PIRMAT in the chemistry department was strongly criticized); iii) PIRMAT should strengthen the links between the CNRS and its industrial partners. ${ }^{28}$ The expert committee charged with implementing the audit's recommendations went even further, and suggested the creation of a materials science department in the CNRS.

Kourilsky rejected this suggestion. In April 1990, he renewed PIRMAT for four years and appointed Gérard Beck as its director. Trained both as a chemist and a metallurgist, Beck had specialized in high-temperature materials for aerospace in Nancy, and developed strong interactions with industry. ${ }^{29}$

Beck developed a clear view about the place and purpose of materials research. For him, "physics or chemistry [were] professions. Materials [was] not a profession" ${ }^{30}$ Materials science was not to be established as a permanent subject in science training and research organizations. Instead, Beck saw materials science as a temporary affiliation motivated by a specific target in the course of a chemist's or a physicist's career. Beck also emphasized possible conflicts of interests between materials scientists and industrials: "Innovations generate conflicts because they destabilize markets" (Beck 1994). While materials scientists aim to design advanced and innovative materials, industrials are more concerned with

\footnotetext{
24 “Schéma prospectif, 20 thèmes stratégiques pour le CNRS", Apr. 1985, CNRS archives' documentary fund, p. 15-17.

${ }^{25}$ A. Percheron-Guégan, interview with E. Bertrand, Apr. 1, 2010.

${ }^{26}$ Letter from J. Hanus to S. Feneuille, Sep. 10, 1986, CNRS archives 000029-33.

27 J. Hanus, letter to F. Kourilsky, Nov. 14, 1989, CNRS archives 000029-35.

28 "Rapport d'audit sur le PIRMAT", Jan. 1990, CNRS archives 010035-14.

${ }^{29}$ G. Beck, interview with E. Bertrand, Feb. 19, 2010.

${ }^{30} \mathrm{G}$. Beck, interview with B. Bensaude-Vincent, Jan. 18, 1996.
} 
optimizing existing materials, and incremental advances. The result is an accumulation of "materials on shelves", i.e. proliferating useless innovations.

This new PIRMAT was part of Kourilsky's global effort to foster interdisciplinarity at the CNRS, which included achieving an equal number of scientific departments and interdisciplinary programs. Based on this engagement in favour of interdisciplinarity, Beck accepted the direction of the new PIRMAT. He introduced a new acronym, SGM, which stands for "Science et génie des matériaux", and was inspired by the English MSE. In front of the PIRMAT Program committee on September 1990, Beck thus summarized the situation: "At the end of the 1970s, materials were a matter of fact; The 1980s were characterized by interdisciplinarity; The 1990s will see unity." Retrospectively he confesses that it was a utopia. $^{31}$

The Beck period of PIRMAT (1990-1994) is characterized by three major features: i) A regular decrease in financial resources; ii) decentralisation resulting in the establishment of six inter-regional networks, and centres for materials science scattered over the French territory; iii) stronger links between PIRMAT and industry. Thanks to a new kind of research program contract (called Contrat de programme de recherche), industry had to fund at least half of the research program budget. A national conference called "Materials: science and industry", in June 1992, was jointly organized by various ministries and state research agencies, and celebrated this reinforced alliance. Researchers coming from large French industrial companies gave all six of the plenary talks.

However, PIRMAT's destiny had been sealed and come to an end in 1994. No new incentive action was launched in 1994, and the budget was not even sufficient to honour PIRMAT's pre-existing commitments. Yet Beck was asked to implement a replacement structure. He invented DIMAT (Materials inter-departmental delegation), a structure with no financial resource, but charged with proposing materials incentive actions to the three relevant CNRS scientific departments. DIMAT was launched on November 11, 1994, under Beck's direction. It had virtually no autonomy and was completely dependent on the scientific departments. Beck's official mission was to represent the CNRS in negotiations with industry, to maintain the visibility of materials research within the CNRS, and to coordinate this research between CNRS laboratories. This weak residue of an ambitious program was very short-lived. In Beck's memory: "It only lasted two or three years. It was just a series of power conflicts. [...] The heads of departments did not want to share their power". ${ }^{32}$ Thus 1997 can be considered the official death date of PIRMAT's successor.

\section{A Failure Story?}

How are we to evaluate PIRMAT in terms of its success in promoting materials research? It is obviously not a success story, and many of the actors we interviewed expressed mixed and bitter feelings about PIRMAT. Yet it is not a complete failure story.

First, the end of PIRMAT by no means implied that materials research disappeared from CNRS laboratories. Nowadays, it seems to be conducted in several niches of chemistry and physics, as was the case before the creation of PIRMAT. Disciplinary affiliations and research programs on optoelectronics, spintronics, surface science, sol-gel, macromolecular chemistry, and so on, have all survived the end of PIRMAT. The PIRMAT governmental initiative was so poorly implemented that it merely created a wave on the surface of a resilient disciplinary structure, with its own dynamics.

\footnotetext{
${ }^{31}$ G. Beck, interview with E. Bertrand, Feb. 19, 2010.

${ }^{32}$ Ibid.
} 
Hence the striking contrast between this short-lived program initiated from the topdown by science policy, and other long-term research projects built from the bottom-up. Ironically, the only thematic action which survived PIRMAT - the ATP "MIAM" (for Milieux aléatoires macroscopiques) - had been started before the creation of PIRMAT (Bideau et al. 2008). MIAM was a bottom-up project, initiated by individual researchers, which lead to flexible networks, rather than a top-down political initiative creating stable institutions. This action also instantiated an alternative approach to materials research: It was not an engineering approach like the US concept of MSE. Instead, it was cognitive research on macroscopic behaviours of specific heterogeneous disordered materials. It focused on the relation between geometrical structure and physical properties, rather than on performance or process.

The story of PIRMAT illustrates the failure of a science policy initiative launched in 1982, but not the failure of materials research in France. In order to identify the weakest links in the chain of decisions that prompted such failure, we got into more details, and found both structural and conjectural reasons.

\subsection{The Choice of the CNRS}

PIRMAT was a victim of CNRS' hegemony in the second half of the twentieth century. The traditional role of CNRS heads of departments was to defend the position and budget of their own discipline, which made them disinclined to promote interdisciplinary research. A disciplinary-structured agency may not seem like the best choice to conduct an interdisciplinary program. Yet interdisciplinary labs flourished in US universities, which were also organized in disciplinary departments.

The choice of the CNRS presented additional shortcomings. Unlike universities, which enjoyed a margin of academic freedom, the CNRS was extremely dependent on the government. Although the CNRS was created to promote the autonomy of scientific research, in reality, its research policy fluctuated according to political changes, and the turnover of its directors followed national elections. Moreover, being an institute with stable laboratories, the CNRS lacked flexibility and quick reactivity to implement short-term multi-actor projects. The US National Science Foundation, for instance, may have been a more appropriate agency because it provided flexible resources for research. In addition, although they did have experience in international work and collaborations, the leaders of PIRMAT worked in a relative isolation.

\subsection{Financial Resources}

However, funding was the most obvious obstacle to the success of the PIRMAT. There was a striking contrast between the explicit ambitions of the governmental initiative, and the limited funds allocated by the CNRS. As Causse bitterly noted, "prospective without funding is nothing". ${ }^{33}$ In 1982, PIRMAT's total budget was 10.3 million FF, most of it from the CNRS. Support from the ministry of research was rather weak and dried-up in 1986. Over the course of its existence, $83 \%$ of PIRMAT's financial resources came from the CNRS, $13 \%$ from the ministry of research, and $4 \%$ from other sources, mostly from the Paris region (Ilede-France). The recently nationalized industries of the 1980 s failed to massively invest in PIRMAT and remained in its margins.

Moreover, the government's financial effort did not last long. Chart 1 below shows that the budget raised from 1982 to 1985 , when its total budget peaked at 26.7 million $1990 \mathrm{FF}$

\footnotetext{
${ }^{33}$ J-.P. Causse, interview with B. Bensaude-Vincent, Mar. 31, 2009.
} 
equivalent. ${ }^{34}$ It remained constant and close to its 1984 level from 1986 to 1989 , at approximately 17 M 1990FF. The noticeable exception was the year 1988, when CNRS departments allocated important funds to PIRMAT, exclusively dedicated to high-temperature superconductors research. From 1989 to 1994, financial resources regularly decreased.

\begin{tabular}{|c|c|c|c|c|c|}
\hline Year & $\begin{array}{l}\text { Total Budget } \\
\text { (Real MFF) }\end{array}$ & $\begin{array}{l}\text { Total Budget } \\
\text { (M 1990FF) }\end{array}$ & $\begin{array}{c}\text { CNRS } \\
\text { contribution } \\
(M \text { 1990FF })\end{array}$ & $\begin{array}{c}\text { Ministry of } \\
\text { research } \\
\text { contribution } \\
\text { (M 1990FF) }\end{array}$ & $\begin{array}{c}\text { Other } \\
\text { contributions } \\
\text { (M 1990FF) }\end{array}$ \\
\hline 1982 & 10.3 & 14.9 & 8.7 & 6.2 & 0 \\
\hline 1983 & 12.4 & 16.4 & 9.9 & 6.2 & 0.3 \\
\hline 1984 & 15.1 & 18.6 & 12.1 & 6.5 & 0 \\
\hline 1985 & 22.9 & 26.7 & 17.5 & 9.2 & 0 \\
\hline 1986 & 14.5 & 16.4 & 16.4 & 0 & 0 \\
\hline 1987 & 16.4 & 18 & 18 & 0 & 0 \\
\hline 1988 & 24.3 & 26 & 20.9 & 0 & 5.1 \\
\hline 1989 & 17.2 & 17.8 & 14.8 & 0 & 3 \\
\hline 1990 & 14.3 & 14.3 & 14.3 & 0 & 0 \\
\hline 1991 & 15.7 & 15.2 & 15.2 & 0 & 0 \\
\hline 1992 & 14.1 & 13.4 & 13.4 & 0 & 0 \\
\hline 1993 & 12.4 & 11.5 & 11.5 & 0 & 0 \\
\hline 1994 & 7 & 6.4 & 6.4 & 0 & 0 \\
\hline Total 82-94 & 196.6 & 215.6 & 179.1 & 28.1 & 8.4 \\
\hline
\end{tabular}

Chart 1: Total budget of PIRMAT between 1982 and 1994, in Million French Francs (MFF) of the considered year ("real MFF") and in MFF of 1990 equivalent, corrected for inflation ("M 1990FF").

Chart 2 shows that $80.5 \%$ of the CNRS contribution came from three departments (Maths and basics physics, Chemistry and Engineering sciences), whilst only $14.5 \%$ came from its dedicated budget (cancelled in 1986). Thus, PIRMAT had to live off the resources of the three disciplinary departments: $40.5 \%$ from chemistry, $38.5 \%$ from physics, and $21 \%$ from engineering sciences. From 1982 to 1988, the physics department was the largest contributor, whereas from 1989 to 1994, it was the chemistry department.

\footnotetext{
${ }^{34}$ In order to make comparisons between different years without being misled by the effects of inflation, we chose to convert all the figures into French Francs of 1990. We thus distinguish between million of real French Francs ("real MFF") and million of French Francs of 1990 ("M 1990FF").
} 


\begin{tabular}{|c|c|c|c|c|c|}
\hline Years & \multirow{2}{*}{$\begin{array}{c}\text { PIRMAT } \\
\text { dedicated } \\
\text { budget line }\end{array}$} & $\begin{array}{c}|c| \\
\text { Mathematics } \\
\text { and basic } \\
\text { physics }\end{array}$ & Chemistry & $\begin{array}{c}\text { Engineering } \\
\text { sciences }\end{array}$ & \\
\cline { 3 - 5 } & (M 1990FF) & Others & \\
\hline $\mathbf{1 9 8 2}$ & 0 & 5.0 & 2.3 & 0.5 & 0.9 \\
\hline $\mathbf{1 9 8 3}$ & 1.3 & 4.4 & 2.2 & 1.1 & 0.9 \\
\hline $\mathbf{1 9 8 4}$ & 4.6 & 3.2 & 2.5 & 1.8 & 0 \\
\hline $\mathbf{1 9 8 5}$ & 10.0 & 2.8 & 2.1 & 2.1 & 0.5 \\
\hline $\mathbf{1 9 8 6}$ & 10.1 & 2.3 & 2.0 & 2.0 & 0 \\
\hline $\mathbf{1 9 8 7}$ & 0 & 4.9 & 6.3 & 3.6 & 3.2 \\
\hline $\mathbf{1 9 8 8}$ & 0 & 9.0 & 7.9 & 3.6 & 0.4 \\
\hline $\mathbf{1 9 8 9}$ & 0 & 4.4 & 6.7 & 3.4 & 0.3 \\
\hline $\mathbf{1 9 9 0}$ & 0 & 5.0 & 6.5 & 2.5 & 0.3 \\
\hline $\mathbf{1 9 9 1}$ & 0 & 4.1 & 6.1 & 3.0 & 2.0 \\
\hline $\mathbf{1 9 9 2}$ & 0 & 4.0 & 6.0 & 3.4 & 0 \\
\hline $\mathbf{1 9 9 3}$ & 0 & 3.6 & 5.3 & 2.4 & 0.2 \\
\hline $\mathbf{1 9 9 4}$ & 0 & 2.8 & 2.3 & 1.3 & 0 \\
\hline Total 82-94 & 26 & 55.5 & 58.2 & 30.7 & 8.7 \\
\hline & & & & & \\
\hline
\end{tabular}

Chart 2: Origin of the CNRS budget for PIRMAT (in M 1990FF).

However, a comparison of PIRMAT's average annual budget with the typical annual budget of a CNRS department shows that PIRMAT never got a budget of the same order of magnitude. For instance, the mean annual budget of the chemistry department (excluding salaries and basic support) was approximately seven times more than PIRMAT's budget.

Nevertheless, over its brief existence, PIRMAT did bring about a number of changes, which call for a closer look.

\subsection{Dispersion}

The two main criticisms addressed to PIRMAT by the audit report of January 1990 were an excessive dependence on CNRS departments, and too little collaboration with industry. ${ }^{35}$

Industrial partnerships gradually increased between 1984 and 1989, but did not prompt new research pathways. They were simply grafted onto existing CNRS research programs.

A significant part of the PIRMAT budget was spent on instrumentation intended for creating materials research centres, similar to the US interdisciplinary labs created in the 1960s. However, the equipment policy did not respond to clear priorities and was excessively dispersed. More generally, in the period 1982-89, 661 actions were undertaken by PIRMAT, including $87 \%$ with budgets under FF 250 000. Nevertheless, since 161 CNRS laboratories benefited from PIRMAT actions over that period, virtually all materials research groups received something from PIRMAT. This may be seen as sowing the seeds of future enterprises.

During the Beck period (1990-1994), industrial collaborations prevailed in PIRMAT. About 60 industrial companies were involved in partnerships with CNRS labs. But this policy was not whole-heartedly approved by the CNRS. During the program committee meeting on June 17, 1993, a delegate from the National committee deplored this industrial orientation and

\footnotetext{
35 "Rapport d'audit sur le PIRMAT", Jan. 1990, CNRS archives 010035-14.
} 
declared the necessity "not to exclusively limit researchers to studies interesting the industry." ${ }^{36}$ Yet the CNRS was the major beneficiary of PIRMAT: 192 CNRS laboratories benefited from the 409 actions undertaken by PIRMAT. In addition, in December 1993, 350 PhDs on themes supported by PIRMAT were in progress in CNRS laboratories. More importantly, PIRMAT also favoured the creation of CNRS/industry joint laboratories, which often outlived PIRMAT. ${ }^{37}$

Finally, in the last years of its existence, PIRMAT represented a real incentive for its partners: Whereas the cumulative budget of PIRMAT for 1991-1994 was only of 49 MFF, its partners, mostly industrial companies, funded CNRS laboratories up to a total amount of 126 MFF. Consequently, between 1991 and 1994, the total funding of the PIRMAT actions was 3.5 times larger (175 MFF) than PIRMAT's total budget (49 MFF).

\subsection{Lack of Independence}

While the intensification of industrial partnerships under Beck's direction addressed one of the problems mentioned in the audit, the lack of independence remained a more serious cause for concern. In fact, Beck had no leverage left to follow the roadmap traced by Causse's report. When PIRMAT lost its autonomous budget, its two successive directors became unable to take any action without the consent of CNRS departments. The number of "thematic programmed actions" (ATP) aimed to encourage physicists, chemists and mechanical engineers to re-direct their research trajectories dropped. From the 1990s onwards, the chemistry, physics and SPI departments behaved like PIRMAT "shareholders". ${ }^{38}$ Since between them they held $100 \%$ of the shares, they were all powerful in imposing their views.

In the late 1980s, while the audit committee examined PIRMAT in France, the American National Research Council published a two-hundred-page report about the orientation of Materials Science and Engineering (National Research Council 1989). This report insisted on the need to intensify the national research effort on both the fundamental and industrial fronts. It recommended an increase of the national budget, and more interactions between universities and industry. Both recommendations were quite similar to those of the French audit committee. However, the US report also insisted on the necessity to reinforce the unity of materials science.

This is seen as a major difference with the French research style, at least by the actors of materials research in France. Friedel contrasted the American and French cases in those terms:

"A materials dynamics developed in the US as a result of a lack of big university research institutes distinct from nuclear, high-energy physics, or space research laboratories, all equipped with big instruments. The situation was about the same in the UK (apart from a few centres such as Cambridge, Oxford, Bristol...). The situation was radically different in Germany (with the Max Planck institutes), and in France with the CNRS", 39

This opinion reverses the usual perspective: Success is attributed to negative causes (lack of academic research agencies), while failure would be due to an excess of research

\footnotetext{
${ }^{36}$ Report of the PIRMAT program committee meeting of June 17, 1993, CNRS archives 010035-14.

${ }^{37}$ For instance, the CNRS/Saint-Gobain joint laboratory, created in January 1990.

${ }^{38}$ The term "shareholder" came in use in Dec. 1, 1993, when one of the department directors complained that the 1994 budget did not "respect the shareholding originally decided for the program (physics $30 \%$, engineering sciences $25 \%$, chemistry $45 \%$ )". Report of the PIRMAT steering committee meeting of Dec. 1, 1993, CNRS archives 010035-14.

${ }^{39}$ J. Friedel, personal communication to B. Bensaude-Vincent, Nov. 18, 2001.
} 
agencies. This account may be an antidote to the prevailing tendency to view the US as the centre of scientific innovation, which provides a model to other countries. However, it may also reveal a strong national bias. Our interviews of CNRS materials scientists suggested a general tendency among French scientists to emphasize the positive role of the CNRS and to reject the US model.

By contrast, the leaders of the French program were more critical. In 1990, the panel chaired by Causse was still an active working group, which wrote annual reports on the state of the art, but was never consulted by the CNRS. In 1990, the panel replaced the routine exercise by a broader assessment of what had been achieved since 1982. This critical selfevaluation acknowledged a number of prospective "errors". ${ }^{40}$ In fact, this list of "errors" became an excuse to stop the annual exercise of review and recommendations, and served to dilute more radical criticisms directly questioning the consistency of the French science policy. Causse's disappointment was explicited in a personal letter he addressed to Hubert Curien, the then Minister of research and technology, together with its report.

He complained about decreasing budgets, emphasizing that the financial plan for 1991 was back to the level of the 1984 budget. And he bitterly concluded: "The project of a great incentive program launched by the 1982 report seems to have been forgotten by now; in fact it has never been applied."

His second target was the CNRS: "The difficulty in dealing with interdisciplinary programs is apparent in the agencies. It is obvious that PIRMAT never got the means needed to implement the CNRS' materials policy".

A third criticism concerned the dispersion of too many under-sized local programs, and lack of national coordination: "In the absence of a real, clearly formulated and effectively managed national program, many of these initiatives lead to a regrettable mess. Regionalization enhanced the disorder. There, again, should be a firmly-established national policy..."

Retrospectively, Causse sees two major reasons for PIRMAT's modest achievements: No funding and no political support. ${ }^{42}$ In his view, materials were a top priority only for Chevènement, who had a broad vision and was prepared to invest a substantial amount of money over a long term, in order to "fill the gaps". But none of his successors at the ministry of research and industry shared his enthusiasm, and they simply considered this program a routine source of funding for daily research.

Neither Causse nor Hanus mentioned the responsibility of industrial companies. Hanus just mentioned in passing that "in the contracts with industry, the CNRS did not always ask for the final report, and was thus able to retain $10 \%$ of the budget. Industry did not deliver its share of the work; That was no secret" ${ }^{43}$ Hanus deplored the attitude of CNRS researchers towards industry. They were reluctant to admit an industrial coordination of the program, as had been recommended by Jean-Louis Beffa, the executive director of Saint-Gobain and an influential member of the CNRS' National committee. Hanus saw this as a missed opportunity for the CNRS: "This [industrial coordination of PIRMAT] might have helped the overall action of the CNRS. But we faced strong opposition: On the one hand, it was out of the question that the 'great capital' should take hold of our 'grey matter'; On the other hand,

\footnotetext{
${ }^{40}$ Their errors of prospective were: the priority to "all-ceramics engine" which never worked, while overlooking the increase of ceramics in housing equipments. In electronics, they had invested in As-Ga semi-conductors, which had no industrial future. Like most people around the world they had not predicted high-temperature superconductivity, and too much money had been invested in the race after the Nobel Prize, in 1986.

${ }^{41}$ J-.P. Causse, letter to H. Curien, minister of research and technology, Mar. 5, 1991.

42 J-.P. Causse, interview with B. Bensaude-Vincent, Mar. 31, 2009.

${ }^{43}$ J. Hanus, interview with B. Bensaude-Vincent, May 16, 2007.
} 
there was little mobility among French CNRS researchers, who lacked a broad vision on things." 44

However, Hanus and his collaborators also mentioned more positive aspects of the program. First, Marie-Claude Vitorge, a researcher who worked for PIRMAT from 1985 to 1989, remembered the exceptional atmosphere created by PIRMAT, with its friendly partnerships and a strict selection process for ATP, which discouraged lobbying. Hanus mentioned significant cooperative results: For instance, some scientific advances on hightemperature materials, or innovations in ceramics for nuclear industry from R\&D conducted by the CEA, their characterization by university or CNRS groups, and synthesis by the COGEMA (Compagnie générale des matières nucléaires). He also mentioned R\&D on quasicrystals, in Vitry, and the creation of a few CNRS/industry joint laboratories...But his effort to remember was interrupted by increasing doubt: Were all these positive aspects really a consequence of PIRMAT?

On March 31, 1992, a year after the working group chaired by Causse delivered its assessment report, the minister Curien officially dissolved the group. In its place, he created two inter-ministerial structures on July 28, 1992: A Council for orientation of materials (COMAT) and an Inter-ministerial group on materials (GIM). The COMAT was tasked with making recommendations for the national policy on materials science, development and technology. But none of these commissions were able to prevent the death of PIRMAT in 1994.

\section{Conclusion}

PIRMAT's destiny exemplifies a number of salient features of the French style in Materials research. First, in stark contrast to the USA and other industrial countries, there was no "materials boom" in France. On the one hand, modest funding and difficulties with the implementation of interdisciplinary structures and academia/industry partnerships are hardly specific to France. On the other hand, the French initiative suffered from the gap between a strong official political will to make materials a top priority in 1982, and a very modest corresponding CNRS budget. It later suffered from political changes and from a high turnover of ministers and CNRS directors. In addition, as a state-funded research agency, the CNRS secured a large autonomy for permanent researchers, and a lack of pressure to raise funds from industry or private foundations.

These structural and conjectural reasons account for the modest results of PIRMAT. However, from the failure of this interdisciplinary program, we should not conclude to the failure of materials research in France. Most of materials research has been conducted in disciplinary laboratories. CNRS researchers had their own concept of materials research, which did not correspond to the close association between science and engineering advocated in Causse's report. The report itself made an ambiguous proposal in seeking to promote a new style of research within existing structures. The engineering approach never prevailed in France. To this day, French materials research has retained an academic disciplinary profile.

How are we to interpret those features? There is no such thing as an anti-materials "French spirit" contrasting with a pro-materials "Americano-British spirit". For those who believe that R\&D policy should be shaped by competition and national rankings, PIRMAT's failure can be seen as the symptom of an intrinsic weakness of the French system. Alternatively, we suggest considering such features as parts of a cultural style shaped by national institutions and traditions, in particular the technophilic inclinations of socialism in France. Hopefully, this biography of PIRMAT, attention to local constraints and

\footnotetext{
${ }^{44}$ Ibid.
} 
circumstances, and a multicultural view of scientific endeavour, may all go some way towards helping plan future national initiatives.

\section{References}

Beck, Gérard. 1994. Les matériaux avancés: problématique et enjeux. Annales des Ponts et Chaussées 71: 4-12.

Bensaude-Vincent, Bernadette. 2001. The Construction of a discipline: Materials Science in the USA. Historical Studies in the Physical and Biological Sciences 31: 223-248.

Bensaude-Vincent, Bernadette, and Arne Hessenbruch. 2004. Materials Science: A field about to explode? Nature Materials 3: 345-346.

Bideau, Daniel, Etienne Guyon, and Jeanne Pullino. 2008. Le tas de sable. Du désordre qui rassemble. La revue pour l'histoire du CNRS 22: 32-38.

Bourdieu, Pierre. 1984. Homo Academicus. Paris: Éditions de Minuit.

Cahn, Robert W. 2001. The Coming of Materials Science. London: Pergamon.

Cottrel, Alan. 2000. A Centennial report. MRS Bulletin 25: 43-46.

DiSalvo, Francis J. 1990. Solid-State Chemistry: A Rediscovered Chemical Frontier. Science 247: 649-655.

Godin, Benoît. 2006. The Linear Model of Innovation: The Historical Construction of an Analytical Framework. Science technology \& Human Values 31, 639-667.

Guthleben, Denis. 2009. Histoire du CNRS de 1939 à nos jours. Paris: Armand Colin.

Krige, John. 2006. American Hegemony and the Postwar reconstruction of Science in Europe, Cambridge: MIT Press.

National Academy of Sciences. 1975. Materials and Man's Needs: Materials Science and Engineering. Supplementary Report. Washington DC: The National Academies Press.

National Research Council. 1989. Materials Science and Engineering for the 1990s. Report of the Committee on Materials Science and Engineering. Washington DC: National Academy Press.

NATO. 1963. Advances in Materials Research in the Nato Nations Organization. Oxford, London, NY: Pergamon Press.

Pestre, Dominique. 1990. Louis Néel, le magnétisme et Grenoble. Récit de la création d'un empire physicien dans la province française. 1940-1965. Cahiers pour l'histoire du CNRS 8: 1-138.

Picard, Jean-François. 1990. La République des savants. La recherche française et le CNRS. Paris: Flammarion.

Roy, Rustum. 1993. The Ideals and Ideas that Led to MRS. MRS Bulletin 18, 9: 84-85.

Shinn, Terry. 1980. The genesis of French Industrial Research 1880-1960. Social Information 19: 607-640.

Shinn, Terry. 1994. Science, Tocqueville and the State. The organization of Knowledge in Modern France (1940-1990), in M.C. Jacob (ed) The Politics of Western Science. New Jersey: Humanity Press, p. 47-80.

Teissier, Pierre. 2007. L'émergence de la chimie du solide en france (1950-2000): de la formation d'une communauté à sa dispersion. PhD Dissertation. University of Paris$\mathrm{X}$.

Voillequin, Baptiste. 2008. Contribution à l'histoire de la catalyse en France (1944-2004). Dynamiques disciplinaires et régimes de production de savoir. $\mathrm{PhD}$ Dissertation. University of Paris-X. 